\title{
Prioritizing Zoonoses for Global Health Capacity Building- Themes from One Health Zoonotic Disease Workshops in 7 Countries, 2014-2016
}

\author{
Stephanie J. Salyer, Rachel Silver, Kerri Simone, Casey Barton Behravesh
}

Zoonotic diseases represent critical threats to global health security. Effective mitigation of the impact of endemic and emerging zoonotic diseases of public health importance requires multisectoral collaboration and interdisciplinary partnerships. The US Centers for Disease Control and Prevention created the One Health Zoonotic Disease Prioritization Tool to help countries identify zoonotic diseases of greatest national concern using input from representatives of human health, agriculture, environment, and wildlife sectors. We review 7 One Health Zoonotic Disease Prioritization Tool workshops conducted during 2014-2016, highlighting workshop outcomes, lessons learned, and shared themes from countries implementing this process. We also describe the tool's ability to help countries focus One Health capacity-building efforts to appropriately prevent, detect, and respond to zoonotic disease threats.

E merging and endemic zoonotic diseases pose a threat not only to the health of animals and humans but also to global health security. An estimated $60 \%$ of known infectious diseases and up to $75 \%$ of new or emerging infectious diseases are zoonotic in origin $(1,2)$. Globally, infectious diseases account for $15.8 \%$ of all deaths and $43.7 \%$ of deaths in low-resource countries $(3,4)$. It is estimated that zoonoses are responsible for 2.5 billion cases of human illness and 2.7 million human deaths worldwide each year (5). Emerging zoonoses are responsible for some of the most high profile and devastating epidemics (6-8); however, endemic zoonoses $(9,10)$ may actually pose a more insidious and chronic threat to both human and animal health. As one comparison, the 2014 Ebola epidemic was responsible for 11,316 deaths and $\$ 2.2$ billion in economic losses (11), whereas each year rabies accounts for $\approx 59,000$ human deaths and roughly $\$ 8.6$ billion in economic losses

Author affiliation: Centers for Disease Control and Prevention, Atlanta, Georgia, USA

DOI: https://doi.org/10.3201/eid2313.170418 worldwide (12). The global impacts of emerging and endemic zoonoses on both human and animal populations make fostering collaboration between human and animal health sectors using a multisectoral, One Health approach a critical step toward improving animal and human health.

Early detection of zoonotic pathogens through enhanced laboratory capacity and surveillance at the animalhuman interface is a crucial step toward controlling and preventing zoonoses (13-20) and a core capacity for implementation of the World Health Organization International Health Regulations 2005 (IHR 2005) and the Global Health Security Agenda (GHSA; https://www.ghsagenda.org/) (21). Rapidly detecting, responding to, and controlling public health emergencies at their source, including those caused by outbreaks of zoonotic diseases, is essential for global health security. However, in low-resource settings, capacity-building efforts should be initially focused on a few key diseases (22). Disease prioritization enables effective capacity building and resource allocation to increase surveillance, guide research, and improve preparedness and response protocols, further advancing global health security and the international health regulations (23-25).

To address this prioritization need, the US Centers for Disease Control and Prevention (CDC) developed the One Health Zoonotic Disease Prioritization (OHZDP) tool $(22,26)$ as a multisectoral approach to rank a country's zoonotic diseases using an objective, semiquantitative method. The OHZDP tool enables a country or region to bring together representatives from human, animal, and environmental health sectors to prioritize the endemic and emerging zoonoses of greatest national concern that should be jointly addressed by human, animal, and environmental health ministries using country- or region-specific criteria. Zoonotic diseases can be prioritized even in the absence of reliable prevalence data by using alternative measures for disease burden so that outcomes are provided in a timely manner, enabling country representatives to give immediate 
feedback, develop action plans, and capitalize on collaborations built during the prioritization process.

During 2014-2016, CDC implemented 7 OHZDP workshops. We summarize overarching themes identified from these workshops and highlight successes and lessons learned to best support additional countries in prioritizing zoonotic diseases by using this tool.

\section{Methods}

CDC conducted OHZDP workshops using methods previously described $(22,26)$. CDC maintains a pool of trained OHZDP workshop facilitators to conduct workshops and to train in-country facilitators to promote country ownership of the prioritization process and to leave the capacity to conduct future prioritization workshops in each country. We interviewed workshop facilitators, reviewed data from workshop materials maintained as part of our routine monitoring and evaluation activities, and reviewed available publications for information on alternate methods and outcomes. Variables collected are number and type of workshop participants by sector (voting members and observers), disease assessment criteria selected during the workshop and the resulting zoonoses rankings, and outcomes or planned next steps for multisectoral capacity building activities. Where appropriate, data for certain variables (e.g., disease ranking criteria) were standardized and combined into larger categories to look for overarching themes. Data were analyzed using Microsoft Excel (Microsoft, Redmond, WA, USA).

\section{Results}

During 2014-2016, at countries' request, CDC conducted OHZDP workshops in Thailand, Kenya (27), Ethiopia (28), Azerbaijan, Cameroon, South Africa, and the Democratic Republic of the Congo. All countries prioritized diseases on a national level; 4 (57.1\%) workshops were specifically conducted to advance GHSA implementation in the country, but all countries had a goal to strengthen multisectoral collaboration and focus laboratory, surveillance, and prevention efforts. All workshops took place over a 2-day period, with an additional 1-2 days for training local facilitators, when requested.

All workshops used standard methods as previously described $(22,26)$ for conducting the preworkshop activities and the in-country facilitated group work. Two countries (Kenya and Thailand) diverged from the standard methods by including more than the recommended number of voting members. Kenya placed voting members into 5 groups, then used group discussion and consensus to assign weights to the individual criteria (27). Thailand held 2 separate, concurrent workshops that produced 2 different outcomes; these outcomes were then combined at a separate meeting held 1 month later to develop a final list of criteria by discussion and consensus. Members were then grouped by their agencies and voted on the ranking or weight applied to each criterion before conducting a final ranking of the diseases.

\section{Facilitators and Participants}

Fourteen CDC-trained OHZDP workshop facilitators were used for the 7 workshops and represented interdisciplinary backgrounds with expertise in zoonoses. A total of 21 incountry facilitators were trained at 5 of the 7 workshops, with an average of 4 (range 2-6) facilitators per workshop. In-country facilitators represented ministries of health $(\mathrm{n}=$ $8)$, agriculture $(n=5)$, environment $(n=1)$, and wildlife ( $n$ $=1)$; research institutes $(\mathrm{n}=2)$; CDC in-country staff $(\mathrm{n}=$ $2)$; and other partners $(\mathrm{n}=2)$. Field Epidemiology Training Program graduates were a resource for in-country facilitators in 2 workshops. Postworkshop debrief meetings and CDC facilitator interviews revealed specific lessons. For example, facilitators who held high-level positions were not available for the entire workshop because of competing priorities. In addition, it was deemed important that incountry facilitators be seen as unbiased during the facilitation process.

A total of 107 voting members participated in the 7 workshops (range 5-33), and multiple sectors were represented (Table 1). The average number of voting members per workshop was 15 , but excluding 2 outlier workshops

Table 1. Sectors represented by voting members, voting members per workshop, and percentage of voting members by sector for One Health Zoonotic Disease Prioritization workshops in 7 countries, 2014-2016*

Sector and no. workshops where present

Median no. voting

Public health, $\mathrm{n}=7$

members/workshop (IQR)

Animal health, $\mathrm{n}=7$

Wildlife, $\mathrm{n}=2$

Research institution, $n=3$

Environmental health, $\mathrm{n}=3$

Local universities, $n=3$

International partners, $\uparrow \mathrm{n}=2$

One Health coordinating mechanism, $n=1$

$5(3-6)$

$5(2.5-6.5)$

$5.5(3.75-7.25)$

$3(2-5)$

$1(1-2)$

$1(1-2)$

$1.5(1.25-1.75)$

$1(1-1)$
$\%$ Total for all workshops (range)

$35.5(16.7-50.0)$

$30.8(16.7-50.0)$

$10.3(0-40.1)$

$10.3(0-25.0)$

$4.7(0-25.0)$

$4.7(0-25)$

$2.8(0-8.3)$

$0.9(0-8.3)$

${ }^{*}$ The total number of voting members for all workshops was 107. Countries: Thailand, Kenya, Ethiopia, Azerbaijan, Cameroon, South Africa, Democratic Republic of the Congo. IQR, interquartile range.

†International partners were the Food and Agriculture Organization of the United Nations, International Livestock Research Institute, and the World Health Organization. 
that grouped voting members (Kenya, $\mathrm{n}=33$; and Thailand, $\mathrm{n}=22$ ), the average was 10 (range 5-11).

Six of workshops included observers from partner organizations or ministries. The number of observers averaged 10 (range 1-26) per workshop. Observers typically included in-country representatives from ministry partners, universities and research institutes, the World Health Organization, the Food and Agriculture Organization of the United Nations, Defense Threat Reduction Agency, the US Agency for International Development and its implementing partners, and CDC.

\section{Zoonotic Disease Lists}

All countries provided an initial list of zoonotic diseases from the relevant ministries to the OHZDP core planning team. Many of these lists were initially created by referencing the countries' human and animal health sector reportable disease lists. The presence of a reportable disease list did not reflect the surveillance capacity, and this variable, if selected, was assessed on-site by in-country subject matter experts. The core planning team conducted an extensive country and regionally specific literature review on the disease list. Voting members reviewed and approved the disease list on the first day of the workshop for use in the prioritization process.

Each list, on average, included 37 (range 25-43) diseases or syndromes. Zoonoses on these lists were classified as $41.4 \%$ (range $27.8 \%-51.3 \%$ ) bacterial, $37.7 \%$ (range $28.0 \%-44.4 \%$ ) viral, $18.3 \%$ (range $13.9 \%-25.0 \%$ ) parasitic, $2 \%$ (range $0 \%-11.1 \%$ ) fungal, and $0.8 \%$ (range $0 \%-$ $4 \%)$ prion in nature. All lists included endemic and emerging zoonotic diseases relevant to the country or region.
All 7 initial country lists included the following bacterial zoonoses: anthrax, brucellosis, leptospirosis, plague, Q fever, salmonellosis, and zoonotic tuberculosis. All lists also included the following viral zoonoses: Crimean-Congo hemorrhagic fever; coronaviruses, including Middle East respiratory syndrome and severe acute respiratory syndrome; flaviviruses, including yellow fever and West Nile; hemorrhagic fever viruses, including Ebola and Marburg; rabies; and zoonotic influenza viruses. Six of the country lists included the following parasitic diseases: cysticercosis or taeniasis, echinococcosis, and toxoplasmosis.

\section{Prioritization Criteria}

Six of the 7 countries selected 5 disease-ranking criteria; 1 country selected 6 criteria. All selected criteria were categorized into 7 overarching topic areas; 4 of those topics were further broken down into 2-3 more specific subtopics (Table 2). All 7 countries ranked diseases on the basis of social, economic, or environmental impact. Six of 7 countries ranked zoonotic diseases on the basis of availability of proven interventions, epidemic or pandemic potential, and severity of disease in humans; 5 ranked zoonoses on the basis of documented presence of disease in the country or region.

When looking at the weighting, or level of importance, voting members assigned severity of disease in humans and epidemic/pandemic potential as the 2 criteria with the highest average weight. Next were documented presence of disease in the country or region, and economic, environmental, or social impact. Last, availability of proven interventions and all other remaining criteria categories were assigned the lowest weight. However, no single criterion stood out across all 7 workshops.

Table 2. Disease ranking criteria chosen by country during One Health Zoonotic Disease Prioritization workshops in 7 countries, 2014-2016*

\begin{tabular}{|c|c|c|}
\hline Disease ranking criteria & No. countries & $\begin{array}{c}\text { Average assigned } \\
\text { weight } † \text { (range) }\end{array}$ \\
\hline Economic, environmental, and/or social impact & 7 & $0.193(0.150-0.210)$ \\
\hline Economic impact only & 3 & \\
\hline Economic and/or social impact & 2 & \\
\hline Economic, environmental, and/or social impact & 2 & \\
\hline Availability of interventions (i.e., vaccines and/or medical treatment) & 6 & $0.183(0.160-0.200)$ \\
\hline Epidemic/pandemic potential (and/or sustained transmission in humans) & 6 & $0.202(0.170-0.220)$ \\
\hline Human-to-human transmission potential & 5 & \\
\hline History of previous outbreaks & 1 & \\
\hline Severity of disease in humans & 6 & $0.206(0.180-0.230)$ \\
\hline Case-fatality rate & 3 & \\
\hline Morbidity and/or mortality rate & 3 & \\
\hline Presence of disease in country and/or region & 5 & $0.200(0.170-0.210)$ \\
\hline Human and/or animal cases of illness reported in country and/or region $\ddagger$ & 4 & \\
\hline Human or animal disease prevalence and distribution in country & 1 & \\
\hline Laboratory capacity/diagnostic testing capacity & 2 & $0.179(0.160-0.198)$ \\
\hline Existing multisectoral collaboration & 2 & $0.183(0.170-0.195)$ \\
\hline Bioterrorism potential & 1 & 0.194 \\
\hline Mode of transmission & 1 & NA \\
\hline
\end{tabular}




\section{Criteria Questions and Responses}

Six of the 7 countries created 1 single or compound question for each selected criterion. One country created 2 separate questions for 4 of their 5 criteria, for a total of 9 questions. Voting members chose ordinal variables for all responses assigned to each criteria question. Seven (17.5\%) questions had a binary response (yes/no), whereas most $(82.5 \%)$ had $\geq 3$ possible responses per criteria question. Regardless of the number of responses per question, all scores were normalized among criteria by using standard OHZDP tool methods (22).

A higher ordinal value (or score) was assigned to the responses for each question that correlated with a more severe, or negative, outcome. For example, a disease with a $50 \%$ case-fatality rate would receive a higher ordinal value than a disease with a $10 \%$ case-fatality rate. For questions that evaluated existing preventive measures, diagnostic capacity, and multisectoral collaboration, a higher ordinal score was given to responses indicating existing capacity or resources. For example, a zoonosis that could be diagnosed in the country would receive a higher score than one that could not.

\section{Zoonotic Disease Ranking}

As a result of the tool's ranking process in these 7 countries, 19 diseases or syndromes were ranked as prioritized diseases (Table 3). Of those, zoonotic influenza virus ( $\mathrm{n}=$ $5)$, rabies $(n=5)$, brucellosis $(n=5)$, and anthrax $(n=4)$ were ranked by the most countries. Four of the 7 countries ranked a mix of endemic and emerging zoonoses; 2 ranked only endemic zoonoses $(27,28)$, and 2 ranked only emerging zoonoses. Of the 4 countries that listed endemic and emerging diseases, on average, $76 \%$ (range $60 \%-83 \%$ ) of the zoonoses on the final list were known to be endemic in the country. Six countries ranked viral, bacterial, and fungal zoonoses, and 2 countries also ranked parasitic diseases; 1 country ranked only viral diseases.

\section{Final Prioritized List of Zoonotic Diseases}

Four of the 7 counties used the original zoonoses produced by the OHZDP tool as their final prioritized list. Two countries agreed to adjust their lists to incorporate other zoonoses that the voting members felt should be in the top 5, and 1 country chose to adjust the order of the rankings to better reflect importance but retained the same zoonoses. Five countries chose a final list of 5 prioritized zoonoses, 1 country chose 6 , and 1 country chose 3 .

The most common zoonoses seen on the final prioritized lists remained the same as the original ranked list with the exception that rabies was selected in an additional country and brucellosis was removed in 1 country (Table 4). Five of the seven countries included both endemic and emerging zoonoses on their final prioritized lists; 69\% (range 33\%-83\%) of these prioritized zoonoses were considered endemic to the country prioritizing the disease. Two countries prioritized only endemic zoonoses $(27,28)$. All of the emerging zoonoses prioritized by each country were viruses. All voting members came to consensus on the final prioritized zoonoses list, modified or not. This final list was then endorsed and adopted by the participating ministries.

\section{Outcomes}

Six of 7 countries planned follow-up activities as part of the workshop. Twenty postworkshop action themes were

\begin{tabular}{|c|c|c|c|c|c|c|c|}
\hline \multirow[b]{2}{*}{ Zoonosis } & \multicolumn{6}{|c|}{ No. countries listing disease, by rank order } & \multirow{2}{*}{$\begin{array}{l}\text { Total no. } \\
\text { countries }\end{array}$} \\
\hline & 1 & 2 & 3 & $4 \dagger$ & $5 \ddagger$ & 6 & \\
\hline Brucellosis (Brucella abortus and B. melitensis) & & 1 & $1 \S$ & $4 \S$ & & & $5 \S$ \\
\hline Rabies & 3 & & 2 & & & & 5 \\
\hline Zoonotic influenza & & & 2 & & 3 & & 5 \\
\hline Anthrax & 2 & 1 & 1 & & & & 4 \\
\hline Hemorrhagic fevers (Ebola/Marburg) & & 1 & & & 2 & & 3 \\
\hline Salmonellosis & & 1 & & 2 & & & 3 \\
\hline Arbovirus infections (e.g., yellow fever and West Nile virus) & & & 1 & & & 1 & 2 \\
\hline Crimean-Congo hemorrhagic fever & 1 & & & 1 & & & 2 \\
\hline Echinococcosis & & 1 & & & & & 1 \\
\hline Hantavirus infection & & & & 1 & & & 1 \\
\hline Hendra virus infection & & & & & 1 & & 1 \\
\hline Leptospirosis & & & & 1 & & & 1 \\
\hline Monkeypox & & & & & 1 & & 1 \\
\hline Nipah virus infection & & 1 & & & & & 1 \\
\hline$Q$ fever & & & & 1 & & & 1 \\
\hline Rift Valley fever & & & & & 1 & & 1 \\
\hline SARS & & & & & 1 & & 1 \\
\hline Trypanosomiasis & & 1 & & & & & 1 \\
\hline Zoonotic tuberculosis (Mycobacterium bovis) & 1 & & & & & & 1 \\
\hline $\begin{array}{l}\text { *Countries: Thailand, Kenya, Ethiopia, Azerbaijan, Cameroon, South } \\
\text { syndrome. } \\
\text { †One country had } 4 \text { diseases that shared the no. } 4 \text { ranking place. } \\
\text { †One country had } 4 \text { diseases that shared the no. } 5 \text { ranking place. } \\
\text { §One country had both } B \text {. abortus and } B \text {. melitensis on its ranked list }\end{array}$ & & & & & & & \\
\hline
\end{tabular}


Table 4. Final combined prioritized list of zoonoses by the One Health Zoonotic Disease Prioritization Tool for 7 countries, 2014-2016*

\begin{tabular}{|c|c|c|c|c|c|c|c|}
\hline \multirow[b]{2}{*}{ Zoonosis } & \multicolumn{6}{|c|}{ No. countries listing disease, by rank order } & \multirow[b]{2}{*}{ Total no. countries } \\
\hline & 1 & 2 & 3 & 4 & 5 & 6 & \\
\hline Rabies & 4 & & 2 & & & & 6 \\
\hline Zoonotic influenza & & & 3 & & 2 & & 5 \\
\hline Anthrax & 2 & 2 & & & & & 4 \\
\hline Brucellosis (Brucella abortus and B. melitensis) & & 1 & $2 \dagger^{*}$ & $2 \dagger^{*}$ & & & $4 \dagger^{*}$ \\
\hline Hemorrhagic fevers (Ebola/Marburg) & & 2 & & 1 & & & 3 \\
\hline Salmonellosis & & 1 & & 1 & & & 2 \\
\hline Zoonotic tuberculosis (Mycobacterium bovis) & 1 & & & & 1 & & 2 \\
\hline Arbovirus infections (e.g., yellow fever and West Nile virus) & & & & & & 1 & 1 \\
\hline Crimean-Congo hemorrhagic fever & & & & 1 & & & 1 \\
\hline Echinococcosis & & & & & 1 & & 1 \\
\hline Leptospirosis & & & & 1 & & & 1 \\
\hline Monkeypox & & & & & 1 & & 1 \\
\hline Rift Valley fever & & & & & 1 & & 1 \\
\hline Trypanosomiasis & & 1 & & & & & 1 \\
\hline
\end{tabular}

identified (Table 5). All 6 countries sought to ensure that the final prioritized list and any after-action items were approved by all participating ministries. Developing or updating and approving some type of national One Health strategy, guiding principles, or workplan was also universally identified as a desired outcome of this prioritization process. Four of the 6 countries indicated plans to use this list to establish recurring meetings, a multisectoral One Health working group or coordinating mechanisms, or both; 1 country that did not list this as an outcome already has a One Health coordination mechanism in place. The remaining action areas focused on various aspects of capacity building (Table 5).

Kenya, which did not plan postworkshop activities, had previously created a One Health strategic plan in 2012 (29). The plan included many of the same capacity-building activities stated by other countries, and prevention and control activities were already under way for 4 of the 5 prioritized zoonoses. Kenya's prioritized list validated existing activities and enabled the Zoonotic Disease Unit, the One Health coordinating mechanism for Kenya, to garner further support from the Government of Kenya to continue these efforts.

\section{Discussion}

During 2014-2016, CDC successfully carried out 7 OHZDP workshops in Thailand, Kenya (27), Ethiopia (28), Azerbaijan, Cameroon, South Africa, and the Democratic Republic of the Congo. Several other tools and methods have been applied to prioritize zoonotic diseases (30-36), but the OHZDP process is unique in that it enables country-led decisions using a multisectoral approach to prioritize both emerging and endemic zoonotic diseases while strengthening One Health collaborations and developing action plans to build capacity for the prioritized zoonoses. In addition, the OHZDP tool can meet the needs of those working in areas where quantitative data on zoonoses are lacking. Last, the OHZDP process provides outcomes in a timely manner so that participants may give immediate feedback and capitalize on One Health collaborations built during the prioritization process.

We have found key successes and lessons learned through the review of these workshops. First, successful outcomes are dependent on trust, transparency, equal representation, and consensus from all relevant sectors participating in the prioritization process and approving the final prioritized list of zoonoses. The CDC-trained OHZDP workshop facilitators not only conduct workshops but also train in-country facilitators to promote country ownership of the process and to build in-country capacity to conduct future workshops. Trained facilitators ensure that the prioritization process is standardized and conducted effectively. We found that using an interdisciplinary team of trained facilitators who remained neutral, unbiased, and did not focus on their specific sector, affiliation, or area of expertise enabled voting members' voices to be heard and recognized. Our review found that most voting members were from the human $(35.5 \%)$ and animal $(30.8 \%)$ health sectors, but additional sectors were represented where available, ensuring the multisector nature of this process.

To accommodate a larger number of voting participants, methods were modified in 2 workshops. However, because these methods have not been rigorously tested, it is still advised that future workshops maintain the recommended number of participants ( 8 to 12 ) to enable more focused discussion during and timely results from the 2-day workshop.

Funding partner advocacy and support of the process and future activities is a potential benefit of observer participation. However, care is needed to ensure that the number of observers in their role as advisors and participants during discussions do not overwhelm or influence the process. Keeping to the recommended $10-15$ total 
Table 5. Categorized action item themes from One Health Zoonotic Disease Prioritization Workshops for 6 countries, 2014-2016*

\begin{tabular}{lc}
\hline Action item themes & $\begin{array}{c}\text { Total no. } \\
\text { workshops }\end{array}$ \\
\hline Obtain ministry approval of prioritized list and & 6 \\
activities & 6 \\
Obtain ministry support of a new or updated & \\
national plan & 5 \\
Develop a national One Health strategy, guiding & \\
principles, or work plan & 4 \\
Identify funding and technical assistance & 3 \\
Create a One Health coordinating mechanism & 3 \\
Improve data sharing across sectors & 3 \\
Establish recurring meetings & 3 \\
Develop disease-specific subcommittees & 3 \\
Strengthen the One Health workforce & 3 \\
Improve community outreach/communication & 2 \\
Improve surveillance & 2 \\
Perform a One Health capacity gap analysis & 2 \\
Link activities back to GHSA/lHR 2005 & 2 \\
Improve reporting & 2 \\
Conduct research studies & 1 \\
Improve or develop laboratory capacity & 1 \\
Improve prevention and control & 1 \\
Improve outbreak response & 1 \\
Evaluate One Health impact & 1 \\
Perform the prioritization on local level & \\
\hline *Countries: Thailand, Ethiopia, Azerbaijan, Cameroon, South Africa, \\
Democratic Republic of the Congo. Kenya was excluded because it had a \\
plan already in place before the prioritization workshop that it continued to \\
support. GHSA, Global Health Security Agency; IHR 2005, International \\
Health Regulations 2005. & \\
\hline
\end{tabular}

observers (26) is needed so that voting members can focus on the workshop process. We recommend having an overview summary at the end of the workshop that is open to a larger group of higher level in-country representatives and other partners to share the workshop outcomes in a timely way.

The OHZDP tool was designed to accommodate diversity in location (i.e., globally) and scale (i.e., local, national, regional) into the prioritization process so participants can select criteria relevant to their needs. We found that most countries were interested in selecting criteria that targeted zoonoses known to be present in country with the following attributions: high illness and death rates in humans; pandemic potential; availability of proven interventions; and economy, environment, or societal impact. Most prioritized zoonoses were endemic diseases, illustrating that countries wanted to first focus their limited resources on diseases for which they could successfully implement enhanced diagnostic capacity, surveillance, and proven interventions.

Common priority action items identified in these workshops are highly relevant to advancing global health security, including improving data sharing between ministries, improving communication to the public, strengthening the One Health workforce, developing disease-specific subcommittees, and increasing general surveillance and outbreak response capacity. Such activities will enhance the capacity of countries to rapidly detect, respond to, and contain public health emergencies, including outbreaks of zoonotic diseases, at their source and thereby ensure global health security. Most countries with identified priority action items planned to use this list to solicit or engage funding partners, which highlights countries taking ownership of the prioritization process, and recognizing and advocating for support around their country-specific priorities. Six countries made sure that the prioritized list and any after-action items were approved by all participating ministries and that a national One Health strategy or multisectoral coordination mechanism was established if it had not been already. By forming or hosting these prioritization workshops with a ministerial One Health coordinating committee, these after-action plans are more readily taken up.

Four of the 7 countries conducted this activity to meet Joint External Evaluation and GHSA zoonotic disease prioritization and collaboration goals. The next step is that these countries then build these plans into their existing activities. These countries are supported by global health partners to help meet these goals.

As part of the continual improvement process for the OHZDP tool, we are employing postworkshop evaluations, in addition to continuing the postworkshop debriefs and facilitator interviews to ensure that these workshop continue to have successful outcomes. Moving forward, lessons learned from OHZDP workshops conducted during 2014-2016 will be applied to standardize and enhance the prioritization process in the future.

All 7 prioritizations were conducted during or in the wake of the 2014 West Africa Ebola outbreak (11). This event likely influenced the outcome for 1 country that prioritized Ebola despite the disease not being endemic or a likely risk in the country or region. Periodically repeating this prioritization process could help eliminate bias from current events, as well as aid in reevaluating if currently prioritized diseases still pose a public health threat, if sufficient capacity has been built, and if newly emerging diseases or other zoonoses need to be considered.

In summary, the GHSA uses a One Health multisectoral approach to strengthen the capacity at the global and national levels to prevent, detect, and respond to human and animal infectious disease threats, whether naturally occurring or accidentally or deliberately spread, that threaten global health security. Both endemic and emerging zoonotic diseases are recognized as being critical for global health security and related efforts. The OHZDP tool aids the GHSA mission by helping countries and regions prioritize their zoonotic diseases of greatest national concern and focusing GHSA capacity-building efforts on improving laboratory capacity, surveillance, outbreak response, and prevention activities on a few key zoonoses at 
first. The OHZDP process also supports progress toward the Joint External Evaluation, specifically for the zoonotic disease indicators, on having national laboratory, surveillance, and joint outbreak response plans and strategies in place for priority endemic/emerging zoonotic diseases with evidence of a multisectoral, coordinated approach. A multisectoral zoonotic disease prioritization with equal engagement from all sectors active in zoonotic disease work is one of the most cost-effective ways a country, especially one with limited resources, can begin using a One Health approach to prevent, detect, and respond to public health threats. By building these capacities and strengthening One Health partnerships for prioritized diseases, a country will not only more effectively address existing diseases but also have the systems in place to be better prepared to detect and respond to new and emerging diseases that may occur and become a threat to global health security.

\section{Acknowledgments}

We thank all of the participating ministries for their engagement in the OHZDP process. In addition, we thank the OHZDP facilitators who conducted these workshops: Mehriban Bagırova, Abednego Baker, Colin Basler, Ermias Belay, Pornpirun Chinnason, Aron Hall, Hashim Hashimov, Benoit Kebela, Grishma Kharod, Paisin Lekcharoen, Nlemba Mabela, Benjamin Monroe, Peninah Munyua, Paidamwoyo Mutowembwa, Megin Nichols, Asaf Omarov, Pawin Padungtod, Emily Pieracci, Wayne Ramkrishna, Cassidy Rist, Carol Rubin, Elshad Rzayev, Onpirun Sagarasearanee, Bencharong Sangkrak, Kendra Stauffer, Kitipat Sujit, Rita Traxler, Marietjie Venter, Deborah Weiss, Jacqueline Weyer, and Shahin Xasiyev.

Dr. Salyer is a veterinary epidemiologist with the Division of Global Health Protection, Center for Global Health, and the One Health Liaison for Global Health in the One Health Office at the Centers for Disease Control and Prevention. Her interests include systems strengthening, global health, One Health, and emerging, zoonotic, and infectious diseases.

\section{References}

1. Woolhouse ME, Gowtage-Sequeria S. Host range and emerging and reemerging pathogens. Emerg Infect Dis. 2005;11:1842-7. http://dx.doi.org/10.3201/eid1112.050997

2. Jones KE, Patel NG, Levy MA, Storeygard A, Balk D, Gittleman JL, et al. Global trends in emerging infectious diseases. Nature. 2008;451:990-3. http://dx.doi.org/10.1038/nature06536

3. Wang H, Naghavi M, Allen C, Barber RM, Bhutta ZA, Carter A, et al.; GBD 2015 Mortality and Causes of Death Collaborators. Global, regional, and national life expectancy, all-cause mortality, and cause-specific mortality for 249 causes of death, 1980-2015: a systematic analysis for the Global Burden of Disease Study 2015. Lancet. 2016;388:1459-544. http://dx.doi.org/10.1016/ S0140-6736(16)31012-1

4. Institute for Health Metrics and Evaluation. Global Burden of Disease Study 2015 (GBD 2015) results. Seattle: The Institute; 2016.
5. Gebreyes WA, Dupouy-Camet J, Newport MJ, Oliveira CJ, Schlesinger LS, Saif YM, et al. The global One Health paradigm: challenges and opportunities for tackling infectious diseases at the human, animal, and environment interface in low-resource settings. PLoS Negl Trop Dis. 2014;8:e3257. http://dx.doi.org/10.1371/ journal.pntd.0003257

6. Nabarro D, Wannous C. The potential contribution of livestock to food and nutrition security: the application of the One Health approach in livestock policy and practice. Rev Sci Tech. 2014;33:475-85. http://dx.doi.org/10.20506/rst.33.2.2292

7. The Kaiser Foundation. The US Government \& Global Emerging Infectious Disease Preparedness and Response. 2014 [cited 2017 Feb 12]. http://files.kff.org/attachment/the-u-s-government-globalemerging-infectious-disease-preparedness-and-response-fact-sheet

8. World Health Organization. Disease outbreak news (DONs). 2017 [cited 2017 Feb 12]. http://www.who.int/csr/don/en/

9. Welburn SC, Beange I, Ducrotoy MJ, Okello AL. The neglected zoonoses - the case for integrated control and advocacy. Clin Microbiol Infect. 2015;21:433-43. http://dx.doi.org/10.1016/ j.cmi.2015.04.011

10. World Health Organization. The control of neglected zoonotic diseases: community-based interventions for prevention and control; 2010 Nov 23-24; Geneva, Switzerland.

11. Centers for Disease Control and Prevention. Cost of the Ebola epidemic. 2016 Aug 8 [cited 2017 Feb 12]. https://www.cdc.gov/ vhf/ebola/outbreaks/2014-west-africa/cost-of-ebola.html

12. Hampson K, Coudeville L, Lembo T, Sambo M, Kieffer A, Attlan M, et al.; Global Alliance for Rabies Control Partners for Rabies Prevention. Estimating the global burden of endemic canine rabies. PLoS Negl Trop Dis. 2015;9:e0003709. http://dx.doi.org/10.1371/journal.pntd.0003709

13. Rabaa MA, Tue NT, Phuc TM, Carrique-Mas J, Saylors K, Cotten M, et al. The Vietnam Initiative on Zoonotic Infections (VIZIONS): a strategic approach to studying emerging zoonotic infectious diseases. EcoHealth. 2015;12:726-35. http://dx.doi.org/ 10.1007/s10393-015-1061-0

14. Childs JE, Gordon ER. Surveillance and control of zoonotic agents prior to disease detection in humans. Mt Sinai J Med. 2009;76:421-8. http://dx.doi.org/10.1002/msj.20133

15. Halliday J, Daborn C, Auty H, Mtema Z, Lembo T, Bronsvoort BM, et al. Bringing together emerging and endemic zoonoses surveillance: shared challenges and a common solution. Philos Trans R Soc Lond B Biol Sci. 2012;367:2872-80. http://dx.doi.org/10.1098/rstb.2011.0362

16. Morse SS, Mazet JA, Woolhouse M, Parrish CR, Carroll D, Karesh WB, et al. Prediction and prevention of the next pandemic zoonosis. Lancet. 2012;380:1956-65. http://dx.doi.org/10.1016/ S0140-6736(12)61684-5

17. Vrbova L, Stephen C, Kasman N, Boehnke R, Doyle-Waters M, Chablitt-Clark A, et al. Systematic review of surveillance systems for emerging zoonoses. Transbound Emerg Dis. 2010;57:154-61. http://dx.doi.org/10.1111/j.1865-1682.2010.01100.x

18. Daszak P, Epstein JH, Kilpatrick AM, Aguirre AA, Karesh WB, Cunningham AA. Collaborative research approaches to the role of wildlife in zoonotic disease emergence. Curr Top Microbiol Immunol. 2007;315:463-75. http://dx.doi.org/10.1007/ 978-3-540-70962-6 18

19. Cutler SJ, Fooks AR, van der Poel WH. Public health threat of new, reemerging, and neglected zoonoses in the industrialized world. Emerg Infect Dis. 2010;16:1-7. http://dx.doi.org/10.3201/ eid1601.081467

20. Grant C, Lo Iacono G, Dzingirai V, Bett B, Winnebah TR, Atkinson PM. Moving interdisciplinary science forward: integrating participatory modelling with mathematical modelling of zoonotic disease in Africa. Infect Dis Poverty. 2016;5:17. http://dx.doi.org/10.1186/s40249-016-0110-4 
21. Global Capacities Alert and Response. IHR (2005) Monitoring and Evaluation framework Joint External Evaluation tool (JEE tool). Geneva: World Health Organization; 2016. p. 98.

22. Rist CL, Arriola CS, Rubin C. Prioritizing zoonoses: a proposed One Health tool for collaborative decision-making. PLoS One. 2014;9:e109986. http://dx.doi.org/10.1371/ journal.pone. 0109986

23. World Health Organization. Strengthening health security by implementing the International Health Regulations (2005) [cited 2017 Feb 12]. http://www.who.int/ihr/about/en/

24. World Health Organization. Setting priorities in communicable disease surveillance. 2006 [cited 2017 Sep 9]. http://www.who. int/csr/resources/publications/surveillance/WHO_CDS_EPR_ LYO_2006_3/en/

25. O'Brien EC, Taft R, Geary K, Ciotti M, Suk JE. Best practices in ranking communicable disease threats: a literature review, 2015. Euro Surveill. 2016;21.

26. Centers for Disease Control and Prevention One Health Office. One Health Zoonotic Disease Prioritization Workshop overview. 2016 [cited 2017 Feb 20]. https://www.cdc.gov/onehealth/pdfs/ zoonotic-disease-prioritization-workshop.pdf

27. Munyua P, Bitek A, Osoro E, Pieracci EG, Muema J, Mwatondo A, et al. Prioritization of zoonotic diseases in Kenya, 2015. PLoS One. 2016;11:e161576. http://dx.doi.org/10.1371/ journal.pone. 0161576

28. Pieracci EG, Hall AJ, Gharpure R, Haile A, Walelign E, Deressa A, et al. Prioritizing zoonotic diseases in Ethiopia using a One Health approach. One Health. 2016;2:131-5. http://dx.doi.org/ 10.1016/j.onehlt.2016.09.001

29. Zoonotic Disease Unit. Kenya One Health strategic plan 2012-2017. 2012 [cited 2017 Feb 21]. http://zdukenya.org/ strategic-plan/

30. Cediel N, Villamil LC, Romero J, Renteria L, De Meneghi D. Setting priorities for surveillance, prevention, and control of zoonoses in Bogotá, Colombia. Rev Panam Salud Publica. 2013; 33:316-24. http://dx.doi.org/10.1590/ S1020-49892013000500002

31. McFadden AM, Muellner P, Baljinnyam Z, Vink D, Wilson N. Use of multicriteria risk ranking of zoonotic diseases in a developing country: case study of Mongolia. Zoonoses Public Health. 2016;63:138-51. http://dx.doi.org/10.1111/zph.12214

32. Havelaar AH, van Rosse F, Bucura C, Toetenel MA, Haagsma JA, Kurowicka D, et al. Prioritizing emerging zoonoses in the Netherlands. PLoS One. 2010;5:e13965. http://dx.doi.org/10.1371/ journal.pone. 0013965

33. Ng V, Sargeant JM. Prioritizing zoonotic diseases: differences in perspectives between human and animal health professionals in North America. Zoonoses Public Health. 2016;63:196-211. http://dx.doi.org/10.1111/zph.12220

34. $\mathrm{Ng} \mathrm{V}$, Sargeant JM. A quantitative and novel approach to the prioritization of zoonotic diseases in North America: a public perspective. PLoS One. 2012;7:e48519. http://dx.doi.org/10.1371/ journal.pone. 0048519

35. Ng V, Sargeant JM. A stakeholder-informed approach to the identification of criteria for the prioritization of zoonoses in Canada. PLoS One. 2012;7:e29752. http://dx.doi.org/10.1371/ journal.pone.0029752

36. $\mathrm{Ng} \mathrm{V}$, Sargeant JM. A quantitative approach to the prioritization of zoonotic diseases in North America: a health professionals' perspective. PLoS One. 2013;8:e72172. http://dx.doi.org/10.1371/ journal.pone. 0072172

Address for correspondence: Stephanie J. Salyer, Centers for Disease Control and Prevention, 1600 Clifton Rd NE, Mailstop C12, Atlanta, GA 30329-4027, USA; email: onehealth@cdc.gov

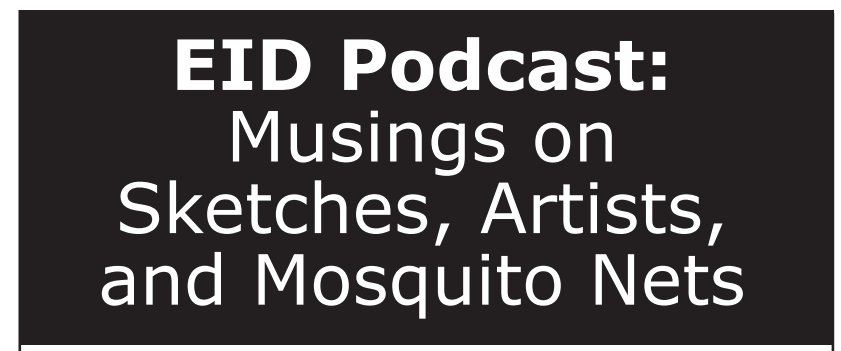

James Abbott McNeill Whistler was born in Lowell, Massachusetts, on July 11, 1834. When he was 9 years of age, his family moved to St. Petersburg, Russia, and there he studied drawing at the Imperial Academy of Science.

In Man at Table beneath Mosquito Net, Whistler himself might be the subject of this black ink drawing, part of a collection of such drawings from 1854 to 1855. Whistler captures the continued struggle of humans versus biting and stinging insects, including those that transmit vectorborne pathogens, from an intimate perspective.

Despite the mosquitoes teeming around him, the man is able to sketch intently and without worry, sheltered by the confines of his personal impenetrable veil. The flurry of cross-hatched, finely scrawled lines in these ephemera could be seen to mimic a mosquito's flight path but this was simply a common technique that Whistler used in his sketches.

Mosquito nets, particularly bed nets or sleeping nets, have, in some shape and form, been used for thousands of years. Herodotus described how people living in marshes in ancient Egypt fished with nets during the day then slept under the same nets to repel insects.

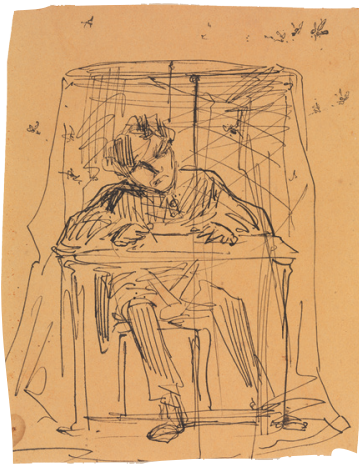

James Abbott McNeill Whistler (1834-1903) Man at Table beneath Mosquito Net, 1854-55. Today, pyrethroid-treated mos-

quito nets are used extensively in malaria-endemic countries in Africa, yielding life-saving returns for little cost.

The World Health Organization reported that in 2012, 207 million cases of malaria occurred, causing an estimated 627,000 deaths, mostly in children under 5 years of age. Today, another aspiring young artist working under his or her mosquito net may be sketching formative works that will someday inspire conversation and comment, and be a prelude of greater things to come, as did Whistler's Man at Table beneath Mosquito Net.

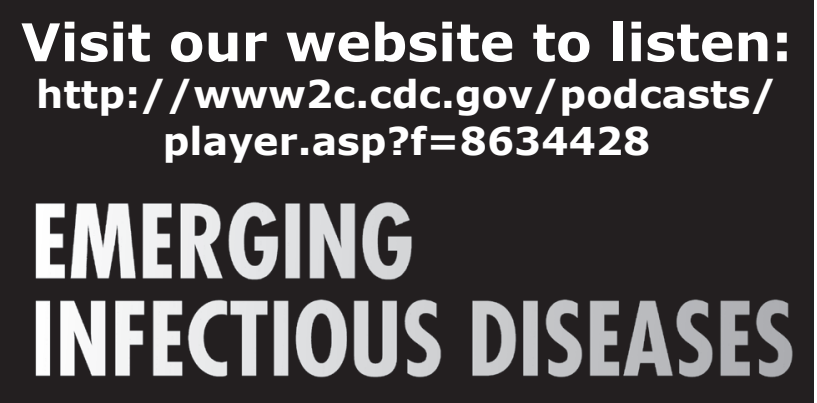

